\title{
A utilização de mídias e TICs nas aulas de Biologia: como explorá-las
}

\author{
Raquel Ruppenthal \\ Tatiana Linhares dos Santos ${ }^{* *}$ \\ Tatiana Valesca Prati***
}

Resumo: Em tempos de constante evolução tecnológica cabe refletir e questionar a integração de mídia e TIC no espaço escolar. A partir dos estudos realizados no curso de Mídias na Educação e aulas aplicadas, descreve-se neste trabalho aulas de Biologia nas quais se utilizaram recursos e estratégias a fim de tornar a aprendizagem dos conteúdos prazerosa e significativa. Observou-se que o uso dessas tornou a sala de aula um espaço mais dinâmico, em que os alunos participaram ativamente na construção de seu conhecimento. Conclui-se que os recursos tecnológicos auxiliam na aprendizagem, mas o papel do professor continua fundamental nos resultados de aprendizagem.

Palavras-chave: Tecnologia, Educação, Mídias, Ensino de Biologia.

Abstract: In times of constant technological change it to reflect and question the integration of media and ICT in school. From

* Professora da rede estadual de ensino/RS. Especialista em Mídias na Educação e Tecnologias da Informação e Comunicação aplicadas a Educação pela UFSM. Mestranda em Educação em Ciências pela UFSM. E-mail: rkruppenthal@gmail.com

** Professora da rede estadual de ensino/RS e rede municipal de Lajeado/RS. Licenciada em Ciências pela ULBRA. Especialista em Mídias na Educação pela UFSM. E-mail: tathy_guedes@hotmail.com

*** Professora da rede estadual de ensino/RS e rede municipal de Farroupilha/ RS.Licenciada em Ciências Biológicas pela UCS. Especialista em Mídias na Educação pela UFSM. E-mail: tvprati@yahoo.com.br 
the studies conducted over the course of Media in Education and applied lessons, is described in this work biology classes in which if it used resources and strategies to make learning enjoyable and meaningful content. It was observed that the use of these became the classroom a more dynamic spaces, where the students participated actively in building their knowledge. We conclude that the technological resources help in learning but the teacher's role remains crucial in learning outcomes.

Keywords: Technology, Education, Media, Biology teaching.

\section{Introdução}

Vive-se a era tecnológica, quando é fácil perceber e observar que crianças e adolescentes são fascinados pela tecnologia e muitas vezes utilizam-na com mais desenvoltura e facilidade que muitos adultos. A tecnologia e a mídia progridem rapidamente; o que hoje é novidade amanhã estará ultrapassado. Em meio a esses novos tempos, é importante refletir e questionar a integração dessas novas mídias na escola, além do novo papel desta na formação dos alunos em tempos de constante evolução tecnológica.

O termo mídia é uma designação para todos os meios de comunicação e respectivos veículos utilizados para divulgar uma informação, uma mensagem. $\mathrm{O}$ aparato utilizado para produzir uma informação também pode ser entendido como outra faceta do termo mídia (PRADO, 2005). O desenvolvimento de novas tecnologias conduz ao surgimento de novas mídias, novas maneiras de comunicação entre as pessoas. Essas inovações fazem repensar o papel da escola na formação dos cidadãos do futuro. Em relação a isso, Moran (2007) é categórico ao afirmar que:

As tecnologias são pontes que abrem a sala de aula para o mundo, que representam, medeiam o nosso conhecimento do mundo. São diferentes formas de representação da realidade, de forma mais abstrata ou concreta, mais estática ou dinâmica, mais linear ou paralela, mas todas elas, combinadas, integradas, possibilitam uma melhor apreensão da realidade e o desenvolvimento de todas as potencialidades do educando, dos diferentes tipos de inteligência, habilidades e atitudes (MORAN, 2007). 
A escola enquanto espaço social de aprendizagem entre pessoas deve se apropriar das tecnologias para tornar a aprendizagem prazerosa. Além do mais, elas permitem inúmeras formas de mostrar um conteúdo, privilegiando todos os sentidos, através da utilização de som, imagem, movimento. Dessa forma, propiciam recursos para os mais variados estilos de aprendizagem.

Se no passado, a escola era o local para obter informações, hoje todos chegam à escola com informações diversas, obtidas na $\mathrm{TV}$, internet ou mesmo pelo rádio. Diante disso, percebe-se que a escola deve se preparar para trabalhar novas habilidades com os estudantes, a fim de que estes tenham uma visão crítica em relação a essas informações, bem como saber comparar, sintetizar essas informaçốes ou então se posicionar com argumentos diante de questões polêmicas. Nesse novo cenário, cabe à escola utilizar as mídias e tecnologias para desenvolver no aluno a habilidade de trabalhar com tantas informações. Conforme Moran (2007):

O aluno nem precisa ir à escola para buscar as informações. Mas para interpretá-las, relacioná-las, hierarquizá-las, contextualizá-las, só as tecnologias não serão suficientes. $O$ professor o ajudará a questionar, a procurar novos ângulos, a relativizar dados, a tirar conclusões (MORAN, 2007).

Assim, nota-se que os tempos exigem uma nova forma de fazer a aula, que começa com o planejamento utilizando as mídias e tecnologias disponíveis na escola, fazendo o uso de estratégias e recursos que estimulem o processo de ensino-aprendizagem, e considerando o aluno um sujeito atuante e corresponsável pela construção de seu conhecimento.

A partir disso, o presente artigo pretende realizar uma breve revisão sobre a relação entre o ensino de ciências e as mídias e Tecnologias da Informação e Comunicação (TIC), além de descrever três planos de aula relativos aos temas ecologia, vírus e animais, aplicados em diferentes séries da educação básica, utilizando como recurso as mídias e TIC. 


\section{As mídias e as TIC no ensino de ciências}

O ensino de ciências visa à formação do indivíduo para a compreensão e participação ativa e crítica no meio em que vive. Essa forma de perceber o ensino de ciências é denominada educação científica ou alfabetização científica. A educação em ciências almeja desenvolver e popularizar o conhecimento científico através de seu uso social além de formar cidadãos que utilizem o conhecimento das aulas de ciências ou biologia para solucionar os problemas do local onde vive (SANTOS, 2007).

Uma das saídas apontadas para nossos alunos atingir a plena educação científica é a mudança dos conteúdos programáticos e também dos processos metodológicos. Para isso, o uso de meios informais de divulgação cientifica, como textos de jornal, revistas, programas de televisão e radiofônicos apresentam-se como estratégias relevantes de contextualização, bem como de aproximação do sujeito com a Ciência (SANTOS, 2007).

Ao levar em conta que mídias são meios que facilitam a comunicação, sejam televisivas, digitais, impressas ou virtuais, conclui-se que no contexto educacional podem servir como auxílio para desenvolver a crítica e questionamento nos alunos, e o educador tem a sua disposição diversas mídias que podem fornecer as situações de aprendizagem necessárias para a construção e o desenvolvimento de habilidades e competências diversas. Nesse contexto, o próprio livro didático é uma mídia, pois comunica e informa. No entanto, ele não deve ser considerado como o único recurso para o desenvolvimento das aulas, pois de acordo com estudo realizado por Razera e colaboradores (2007) aulas tradicionais (que utilizam apenas o livro) não motivam e geram desinteresse por parte deles. Por outro lado, a diversidade de recursos, bem como de metodologias variadas, estimulam o aluno para a participação dinâmica e criativa, potencializando o aprendizado. Estudo realizado por Martinho (2009) conclui que

a implementação das TIC na Educação em Ciências proporcionou a criação de um ambiente de trabalho mais motivador, onde os alunos 
focalizaram mais a sua atenção, ficaram mais empenhados e rigorosos no desenvolvimento dos seus trabalhos, conseguindo-se também melhores resultados em termos de avaliação (MARTINHO, 2009, p. 536)

Através das TIC e da utilização de mídias diversas, é possível que a sala de aula seja um ambiente atrativo às crianças e jovens, uma vez que estes vivem as tecnologias, seja através dos games, dos celulares, do computador entre tantos outros. Assim, percebe-se que as TIC representam um potencial enorme para a educação, inclusive no ensino de ciências. E de que formas elas podem ser utilizadas? Como ferramentas que auxiliem o processo de aprendizagem, seja para pesquisa, armazenamento seja para divulgação de dados.

As TIC podem ser utilizadas como uma ferramenta no preenchimento de tabelas e na construção de gráficos e bases de dados adequadas à faixa etária dos alunos; como uma fonte de referência utilizando informação contida em CDROM e na Internet; como um meio de comunicação através do uso do correio eletrônico, da discussão online, das apresentações em PowerPoint, da apresentação de imagens digitais e da utilização de quadros interativos; e como um meio para exploração com recurso a programas de programação básica e de simulação (MURPHY, 2003 apud MARTINHO, 2009, p. 530).

No entanto, apenas a utilização de mídias e TIC não mudará o quadro da educação em Ciências. Elas de fato representam estratégias potenciais para a aprendizagem, mas sozinhas correm o risco de apenas "modernizar" as aulas tradicionais. Além disso, é importante que aconteça a reestruturação dos currículos e a mudança metodológica por parte do educador. A utilização de mídias e TIC como ferramenta de ensino requer uma mudança postural por parte do professor, que deve ter um perfil pesquisador, curioso e que goste das tecnologias, que as vejam como aliadas e não rivais. Ao mesmo tempo, é necessário estar sempre buscando as novidades tecnológicas, refletir seu uso na educação e as possíveis adaptações em relação ao espaço e tempo do trabalho em sala de aula. Portanto, é necessário abordar a Ciência de forma sistêmica, transdisciplinar e contextualizada, promovendo, 
consequentemente, uma educação que possibilite aos cidadãos a apropriação de conhecimentos com base nos quais possam tomar decisões conscientes e esclarecidas. Pois

[...] conhecer não é apenas reter temporariamente uma multidão de noções anedóticas ou enciclopédicas [...]. Saber significa primeiro, ser capaz de utilizar o que se aprendeu, mobilizá-lo para resolver um problema ou aclarar uma situação (GIORDAN, 1996, p. 11).

Isso inclui ver e entender uma notícia relativa à ciência que seja veiculada nos diversos meios de comunicação e ser capaz de emitir uma opinião com argumentos, posicionar-se contra ou a favor sobre temas polêmicos ou não. Mas como desejar alunos assim sem reestruturação do sistema escolar?

De acordo com Ausubel, os conteúdos trabalhados na escola precisam ter significado para os alunos (Ausubel citado por Coll, 1999). Além de significativos, devem considerar os conhecimentos prévios de quem aprende e ensina. Os temas estudados nas Ciências Naturais, além de presentes diariamente nas mídias (TV, rádio, impressos, internet), são assuntos sobre os quais todos trazem algum conhecimento até a escola, cabendo a esta desenvolver ou aprofundar o conhecimento através da proposição de situações desafiantes.

Dentre os temas normalmente presentes na mídia e que são trabalhados durante a educação básica estão os vírus, a ecologia e os animais. Durante a realização da especialização em Mídias na Educação, tiveram-se diversos momentos de reflexão sobre a nossa prática em sala de aula, bem como momentos de planejamento e aplicação da teoria sobre mídias em nossas aulas. Assim, desenvolveram-se três planejamentos, relativos a vírus, ecologia e animais, que foram aplicados em escolas públicas da rede estadual e municipal e que estão descritos na sequência.

Todos os planejamentos utilizaram-se de mídias e TIC diversas, objetivando fazer o aluno ter um papel ativo na construção de conceitos e na produção de material. A produção de material é importante, pois segundo Moran (2007), "uma mudança significativa - que vem acentuando-se nos últimos anos - é a necessidade 
de comunicar-nos através de sons, imagens e textos, integrando mensagens e tecnologias multimídia”. Por isso, as atividades desenvolvidas procuraram ao máximo explorar essas linguagens.

\section{Breve descrição das aulas e mídias utilizadas}

Apesar dos temas estudados em Ciências e Biologia serem interessantes e da curiosidade dos alunos, é comum a queixa de que há "muitos nomes e palavras para saber". Outro fator que interfere no aprendizado, segundo os alunos e também de nossas observações, é a falta de movimento na aula. Vários alunos queixam-se de aulas que são apenas leitura do livro didático. Considerando essas observações e as reflexôes realizadas no curso de Mídias na Educação, implementaram-se três planejamentos, descritos nos itens que seguem.

\section{Ecologia}

O planejamento de ecologia foi desenvolvido com três turmas do $2^{\circ}$ ano do Ensino Médio. A proposta envolveu diversos recursos diferentes, a fim de superar o uso exclusivo do livro didático. Os principais conteúdos abordados foram Ecossistemas: conceitos básicos; Níveis tróficos, Flutuações populacionais e Biomas brasileiros. Segue a descrição dos principais momentos.

Após observação dos constituintes bióticos e abióticos do ambiente e das suas relações, propôs-se a construção de um ecossistema terrestre (terrário) a fim de que os alunos pudessem visualizar o que acontece num ecossistema e perceber a relação de dependência do meio biótico e abiótico. Ao mesmo tempo, foi possível observar o ciclo da água e estabelecer hipóteses se ocorressem modificações no terrário construído. Além disso, foi possível aos alunos compreender bem a diferença entre biótico e 
abiótico. Após as discussões, realizou-se o confronto das ideias obtidas com livros e então o registro da aula nos cadernos. Alguns alunos construíram seus próprios terrários em casa.

Uma vez percebida a relação entre os seres vivos e o meio físico, passou-se a trabalhar as relações entre os seres vivos, a noção de níveis tróficos, cadeias e teias alimentares. Inicialmente, elaborou-se a cadeia alimentar de um aluno no quadro. Após as discussões e organização de ideias, foi proposto aos alunos a confecção de cadeias e teias alimentares utilizando a técnica de recorte e colagem, em pequenos grupos. Ao concluir a tarefa, houve a socialização dos trabalhos e discussão final.

Para perceber o efeito de presas e predadores numa população, utilizou-se uma brincadeira semelhante ao pega-pega: milhos, lebres e tigres (adaptada de KRASILCHIK, 2008). A brincadeira foi realizada no pátio escolar, onde foram coletados os dados para a posterior discussão e elaboração de gráficos para visualizar o efeito de presas e predadores em uma população. Como a sala de aula digital não estava em funcionamento na época, optou-se por traçar os gráficos manualmente.

Para finalizar, realizou-se o estudo dos biomas brasileiros. Para isso, e considerando um pedido dos alunos, optou-se a realização de trabalhos de pesquisa em grupo para apresentação. Mas o diferencial foi que eles poderiam utilizar os meios disponíveis na escola para a apresentação, tais como o projetor multimídia e DVD. Todos os grupos receberam um roteiro para auxiliar na elaboração do trabalho. Ao final do tempo previsto para as pesquisas, as apresentações, que surpreenderam.

A escolha das estratégias e mídias não deve ser ao acaso. Em cada uma das etapas, percebeu-se a potencialidade de uma mídia diferente. $\mathrm{O}$ fato de utilizar técnicas diferentes, como montar um ecossistema, utilizar uma brincadeira ou técnicas das Artes fez com que os alunos se motivassem para participar das aulas, deu a movimentação necessária para mobilizar a construção de conceitos. Ao serem questionados ou incentivados a escrever sobre as atividades realizadas, foi possível perceber que o aprendizado 
ocorreu. Não eram palavras copiadas, mas sim, escritas ou faladas a partir do conhecimento construído por eles em cada etapa.

Mas o fato mais marcante dessa trajetória, com certeza, foi o fato dos alunos produzirem uma apresentação sobre os biomas. Nem todos sabiam como fazer uma apresentação no PowerPoint. Mas eles buscaram ajuda com os colegas ou mesmo com a monitora do Centro de Inclusão Digital. As produções basicamente utilizaram o PowerPoint, mas também houve grupos que utilizaram o MovieMaker. Conforme Razera (2007):

Uma apresentação no PowerPoint pode ter como objetivo a discussão de um tema, o desenvolvimento de uma investigação, a representação de ideias ou conceitos que promovam a construção de novos conhecimentos. Para elaborar uma apresentação, o executor terá de pesquisar, analisar, selecionar, sintetizar, organizar e articular informações sobre o tema, criando telas (slides) que articulem a forma de representação e o conteúdo em estudo (RAZERA, 2007, p. 85).

O mesmo é reiterado por Valente (2001, p. 23), quando afirma que "os recursos da informática não ensinam e nem fazem aprender, mas se constituem ferramentas pedagógicas”. Ou seja, o computador é um ambiente interativo, que potencializa a aprendizagem de habilidades diversas como o investigar, analisar, comparar, levantar hipóteses, testá-las e refinar suas ideias iniciais, construindo, assim, seu próprio conhecimento.

Ficou claro a partir da proposta que o computador não é indispensável. Ele é uma ferramenta importante, mas não a única. Outros meios, como brincadeiras e produções práticas também mobilizam o aluno na desenvolvimento das diversas habilidades. Conforme falas ouvidas dos alunos, aquelas foram as melhores aulas do ano.

\section{Vírus}

Sabe-se que desde a Antiguidade animais e plantas são infectados por doenças. Convive-se com eles desde nosso nascimento, e ao longo da vida, por várias vezes nosso corpo é 
invadido pelas mais variadas formas virais. Eles invadem nossas células, as utilizam para multiplicar-se e as destroem. Nesse contexto, faz-se necessário uma abordagem ampla sobre o assunto a fim de que os alunos realmente compreendam e apliquem esse conhecimento em sua vida.

Inicialmente foi realizada uma aula expositiva, utilizando o retroprojetor para ilustrar o conteúdo sobre vírus. Após, os alunos ( $3^{\circ}$ ano do Ensino Médio) foram convidados a pesquisar sobre outros vírus e também as doenças causadas por eles. Essa pesquisa foi esquematizada no caderno e, após, socializada e discutida no grande grupo.

O momento diferencial da proposta foi a criação de histórias em quadrinhos (HQs) nas quais os alunos teriam que informar com linguagem simples, explicando a transmissão e a prevenção de uma DST. Essas HQs foram lidas na turma, e depois foi feita uma exposição na biblioteca da escola a fim de que outros alunos pudessem obter informações.

A história em quadrinhos é uma forma de produção textual que utiliza e organiza os conhecimentos construídos para comunicar uma informação para outras pessoas. A confecção de história em quadrinhos pode ser utilizada como um exercício ou mesmo como uma forma de avaliação. Segundo Giovanetti (2005):

A história em quadrinhos (HQ) é uma arte sequencial, formada por dois signos gráficos: a imagem e a escrita, por isso, é fruto da literatura e do desenho e em geral apresenta onomatopeias, palavras que procuram reproduzir ruídos ou sons. A sua origem se remonta ao início da civilização, onde as inscrições rupestres nas cavernas já revelavam a preocupação de narrar os acontecimentos através de desenhos sucessivos (GIOVANETTI, 2005).

A partir do que foi dito acima, observa-se que as $H Q$ s reforçam a imaginação do educando, fortalecendo a construção da aprendizagem. Kamel (2006) afirma que utilizar as HQ na escola amplia leituras e interpretações do mundo, e pelo fato de serem publicações de cunho popular, existe relação com o contexto do aluno. Segundo Caruso e Silveira (2009), 
[...] as HQ têm a capacidade de atrair o jovem leitor e esse fato está fazendo com que os educadores aproveitem cada vez mais esse instrumento, pois a sua utilização valoriza as situações do cotidiano e da vivencia das crianças e jovens (CARUSO; SILVEIRA (2009) citado por CABELLO, 2009-2010, p. 89).

A construção de HQs pelos alunos é uma atividade envolvente e rica em oportunidades para corrigir dúvidas e erros e pode ser utilizadas nas variadas disciplinas do currículo escolar. A atividade realizada demonstrou-se produtiva, uma vez que os alunos tiveram papel ativo na construção da HQ. E é isso que se espera dos alunos: que eles possam utilizar aquilo que aprenderam para auxiliar na resolução de problemas e dúvidas do seu dia a dia. Ao adaptar aquilo que haviam aprendido para uma linguagem simples, os alunos mobilizaram a capacidade de síntese, além de estarem comunicando algo sobre DSTs para seus colegas mais jovens.

\section{Animais}

A terceira sequência desenvolvida refere-se ao estudo dos mamíferos, na qual os alunos puderam vislumbrar os diversos aspectos dessa classe animal da qual também fazemos parte. Nesse planejamento os alunos ( $6^{\mathrm{a}}$ série do Ensino Fundamental) também tiveram papel ativo na elaboração de seu conhecimento, como será descrito a seguir.

Os alunos foram organizados em grupos para realizar pesquisa referente aos mamíferos, em meios diversos. Nessa etapa, os grupos tiveram que selecionar informações que considerassem relevantes, utilizando o editor de texto Word, de maneira a esboçar quais dados seriam utilizados para elaborar uma apresentação com o Power Point e/ou MovieMaker.

Durante a utilização do editor de texto, os alunos foram orientados a estruturar os trabalhos conforme normas preestabelecidas de margem, fonte, parágrafo, espaçamento, bordas entre 
outros. Cabe ressaltar, que esses tipos de normas, proporcionam aos alunos uniformidade no trabalho na hora de serem avaliados.

A culminância da atividade foi a apresentação das informações para os demais colegas, utilizando-se de projetor multimídia, computador e telão. Esse momento foi oportunizado a fim de que os alunos desenvolvam a oralidade e o falar em público, bem como a utilização das tecnologias disponíveis na escola como ferramentas na aprendizagem.

\section{Conclusão}

Ao término da aplicação dos planejamentos elaborados utilizando recursos diversos, percebe-se que a motivação dos alunos para as aulas foi maior do que nas aulas tradicionais. Podemos afirmar que, o uso de estratégias diferenciadas e a valorização das mídias no espaço escolar renderam bons resultados também em nível de aprendizagem, levando em conta que os alunos construíram novos esquemas de conhecimento (COLL, 1999). Isso foi verificado através do diálogo com os alunos e também avaliando as produções deles. Constatamos, assim como Razera (2007) e Martinho (2009), que a utilização de recursos tecnológicos é motivante e torna a aprendizagem mais atraente e prazerosa.

Conforme Razera et al (2007), para os conteúdos de Biologia, os recursos de multimídia apareceram como um diferencial, pois auxiliam na aprendizagem. Mas verificamos que o papel do professor continua fundamental nos resultados de aprendizagem, pois muito além do transmitir informações, passa-se a mediar, dialogar, perguntar, motivar o aluno no caminho da aprendizagem.

O fato de não utilizar apenas o livro torna a sala de aula mais dinâmica. Além disso, os alunos querem ser protagonistas de atividades diferentes, na qual eles tenham que usar a criatividade e o potencial criador deles na resolução de algum problema ou desafio. $\mathrm{E}$ isso foi muito bem colocado nas palavras de um aluno, quando diz que "a turma estava muito entusiasmada e foi 
uma maneira de 'pegar' bem o conteúdo e mostrar que somos capazes de organizar uma apresentação mostrando para a turma o que aprendemos".

Percebe-se que nos três planejamentos com o uso de mídias e tecnologias disponíveis, houve participação e envolvimento, superando as dificuldades iniciais de prestar atenção, compreender o vocabulário utilizado e mesmo sair da passividade para o protagonismo em sala de aula. O trabalho cooperativo também foi um aspecto interessante na realização do trabalho.

Enfim, os recursos estão disponíveis, e se mostram como ferramentas eficazes para que os alunos participem das aulas ativamente. Mas ainda se faz necessária a formação contínua de professores para o uso pedagógico das mídias e principalmente a vontade de modificar as práticas docentes e inovar as metodologias no ensino de Ciências.

\section{Referências}

CABELlO, Karina S. A.; MORAES, Milton Osório. Como uma cartilha para falar de hanseníase transformou-se em história em quadrinhos. Revista Ciência e Ideias. v. 1, n. 1, out./mar. 2009-2010. Disponível em: $<$ http://www.ifrj.edu.br/revista/index.php/revistacienciaseideias/search/ titles>. Acesso em: 25 jul. 2010.

COLL, César. Psicologia e Currículo. São Paulo: Ática, 4. ed. 1999

GIOVANETTI Aparecida Richena. A vida em tiras. Centro Universitário das Faculdades Associadas de Ensino. Disponível em: <http://www.unifae-sj.edu.br/Noticias/n180.html> Acesso em: 24 jul. 2009

GIORDAN, André; VECCHI, Gérard de. As origens do saber: das concepções dos aprendentes aos conceitos científicos. 2 Ed. Porto Alegre: Artes Médicas, 1996.

KAMEL, Cláudia Rosa Lúcio. Ciências e quadrinhos: explorando as potencialidades das histórias como materiais instrucionais. Dissertação (Mestrado em Ensino de Biociências e Saúde) - Instituto Oswaldo Cruz/ FIOCRUZ, Rio de Janeiro, 2006. 
KRASILCHIK, Myriam. Prática de Ensino de Biologia. São Paulo: Editora da Universidade de São Paulo, 2008.

MARTINHO, Tânia; POMBO, Lúcia. Potencialidades das TIC no ensino das Ciências Naturais - um estudo de caso. Revista Electrónica de Enseñanza de las Ciencias. v. 8, n. 2, 2009.

MORAN, José Manuel. As mídias na educação. In: Desafios na Comuni-

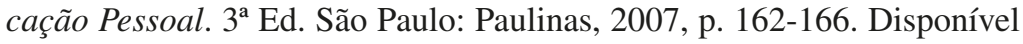
em <http://www.eca.usp.br/prof/moran/midias_educ.htm> Acesso em: 20 jul. 2010.

PRADO, Maria Elisabette Brisola Brito. In: Integração das Tecnologias na Educação. Salto para o Futuro. ALMEIDA, Maria Elizabeth B. de; MORAN, José Manuel (Orgs.), p. 12-17, 2005.

RAZERA, Julio César Castilho; BATISTA, Rosângela Miranda Silva; SANTOS, Roque Pereira. Informática no ensino de biologia: limites e possibilidades de uma experiência sob a perspectiva dos estudantes Experiências em Ensino de Ciências. v. 2, n. 3, p. 81-96, 2007.

SANTOS, Wildson Luiz Pereira dos. Educação científica na perspectiva de letramento como prática social: funções, princípios e desafios. Revista Brasileira de Educação, v. 12, n. 36. set./dez. 2007.

VALENTE, José Armando. Formação de professores para o uso da informática na educação. In: Brasil. Ministério da Educação. Experiências usando a educação a distância. (Proinfo). Brasília: Ministério da Educação. 2001. 